\title{
Familial occurrence of carpal tunnel syndrome
}

\author{
Piotr Puchalski, Zbigniew Szlosser, Andrzej Żyluk \\ Department of General and Hand Surgery, Pomeranian Medical University in Szczecin, Poland
}

\begin{abstract}
The objective of this study was to investigate the incidence of familial carpal tunnel syndrome in patients admitted to the authors' institution for carpal tunnel release. Questionnaires completed by 120 patients: 92 women (77\%) and 28 men (23\%) at a mean age of 56 years at their baseline clinical examination were reviewed. Familial occurrence of the disease was noted in 21 patients (17\%): 16 women and five men. Three family members were affected in three patients, two relatives in eight patients, and one relative in 10 patients, giving a total of 35 affected relatives. The patients' sisters $(n=16)$ were the most commonly involved, followed by mothers $(n=12)$, daughters $(n=2)$, brothers $(n=2)$, grandmothers $(n=2)$ and an aunt $(n=1)$. Bilateral manifestation of the disease was noted in 19 patients $(90 \%)$ and in $31(88 \%)$ of their affected relatives. The results suggest that carpal tunnel syndrome shows a moderate tendency to familial occurrence and, if so, it usually manifests bilaterally.

Key words: carpal tunnel syndrome, inheritable traits, familial predispositions, bilateral presentation (Neurol Neurochir Pol 2019; 53 (1): 43-46)
\end{abstract}

\section{Introduction}

Controversy has been considerable regarding the incidence of familial occurrence of carpal tunnel syndrome (CTS). Individual families have been reported where most of the members have been affected, and the results of some population-based studies have shown a higher incidence of the condition among relatives of some patients. The first report of the occurrence of CTS among members of the same family was made in 1959 [1]. A decade later, Phalen noticed that a proportion of his CTS patients had declared occurrence of the same symptoms in their family members, suggesting familial predisposition to the syndrome [2]. These findings were confirmed by Radecki, who showed that 165 of $421 \mathrm{pa}-$ tients (39\%) operated on for CTS had relatives suffering from the same symptoms in their hands [3]. The author suggests that inheritable carpal tunnel syndrome may be caused by biochemical, developmental or anatomical changes of the carpal tunnel. In contrast, on the basis of literature reviews, other authors have found that true inheritable carpal tunnel syndrome occurs very rarely [4].

The objective of this study was to investigate the incidence of familial carpal tunnel syndrome in patients admitted to the authors' institution for carpal tunnel release.

\section{Materials and methods}

Questionnaires completed at baseline clinical examination by 120 patients with CTS admitted to the authors' institution between December 2017 and March 2018 (a period of four months) were reviewed. The approval of the Bioethical Council of the local Medical University was obtained for funding the Carpal Tunnel Syndrome Register and for performance of further analyses. Informed consent was obtained from all subjects before enrolment. There were 92 women $(77 \%)$ and 28 men (23\%) with a mean age of 56 years (range 33-84).

The diagnosis of CTS was made on the basis of clinical and electrophysiological grounds. In all of these patients, nerve conduction studies were positive, confirming the diagnosis. The following grading scale of the severity of electrophysiological abnormalities was used in our study:

Grade I (mild). Decreased sensory nerve conduction $(<40 \mathrm{~m} / \mathrm{s})$ and SNAP recordable with normal $(\geq 10 \mu \mathrm{V})$ or decreased $(1-9 \mu \mathrm{V})$ amplitude. DML normal or slightly prolonged (3.5-4.0 ms). CMAP normal $(\geq 4 \mathrm{mV})$. Normal EMG recording from APB.

Grade II (moderate). SNAP non-recordable. DML prolonged $>4 \mathrm{~ms}$. CMAP normal or decreased $(2-4 \mathrm{mV})$. Normal or moderately neurogenic EMG recording from $\mathrm{APB}$.

Address for correspondence: Piotr Puchalski, Department of General and Hand Surgery, Pomeranian Medical University in Szczecin, Poland, e-mail: piotrpuch@onet.poczta.pl 
Table 1. Demographic and clinical data obtained from patients with familial carpal tunnel syndrome

\begin{tabular}{|c|c|c|c|c|c|c|c|c|}
\hline ID & Sex & Age & $\begin{array}{c}\text { Duration } \\
\text { of CTS }\end{array}$ & Affected relatives & $\begin{array}{l}\text { Time of onset of CTS } \\
\text { in relatives }\end{array}$ & Hand involved & Comorbidities & Treatment \\
\hline 1 & $\mathrm{~F}$ & 67 & $20 y$ & 2 sisters & 10 and 20 years ago & Bilateral & No & Not operated \\
\hline 2 & $\mathrm{~F}$ & 78 & $1 y$ & 2 daughters & 2 and 4 years ago & Bilateral & No & 1 operated \\
\hline 3 & M & 55 & $2 y$ & Mother & 15 years ago & Bilateral & Diabetes & Not operated \\
\hline 4 & $F$ & 69 & $10 y$ & 2 sisters & 19 years ago & Bilateral & No & 1 operated \\
\hline 5 & M & 56 & $10 y$ & Sister & 5 years ago & Left & Thyroidectomy & Not operated \\
\hline 6 & $\mathrm{~F}$ & 35 & $1 y$ & Mother and aunt & 18 and 7 years ago & Bilateral & No & Not operated \\
\hline 7 & $\mathrm{~F}$ & 51 & $5 y$ & Sister & 7 years ago & Bilateral & No & Operated \\
\hline 8 & $\mathrm{~F}$ & 55 & $5 y$ & Mother & 10 years ago & Bilateral & No & Operated \\
\hline 9 & $\mathrm{~F}$ & 49 & $10 y$ & Sister & 9 years ago & Bilateral & No & Operated \\
\hline 10 & $\mathrm{~F}$ & 45 & $8 y$ & Mother & 15 years ago & Right & No & Not operated \\
\hline 11 & M & 65 & $2 y$ & 2 brothers and sister & 4 years ago & Bilateral & No & Not operated \\
\hline 12 & M & 51 & $7 y$ & Mother, sister & 15 and 10 years ago & Bilateral & No & Operated \\
\hline 13 & $\mathrm{~F}$ & 59 & $1 y$ & Sister & 3 years ago & Right & No & Not operated \\
\hline 14 & $F$ & 57 & $2 y$ & Mother, sister & 3 and 2 years ago & Bilateral & No & Not operated \\
\hline 15 & $F$ & 51 & $2 y$ & Grandmother & 30 years ago & Bilateral & No & Operated \\
\hline 16 & $\mathrm{~F}$ & 33 & $1 y$ & $\begin{array}{l}\text { Grandmother, mother, } \\
\text { sister }\end{array}$ & $3-30$ years ago & Bilateral & No & 1 operated \\
\hline 17 & M & 51 & $7 y$ & Mother, sister & 15 and 10 years ago & Bilateral & No & Operated \\
\hline 18 & $\mathrm{~F}$ & 59 & $1 y$ & Sister & 3 years ago & Right & No & Not operated \\
\hline 19 & $\mathrm{~F}$ & 57 & $2 y$ & Mother, sister & 3 and 2 years ago & Bilateral & Diabetes & Not operated \\
\hline 20 & $F$ & 51 & $2 y$ & Mother & 30 years ago & Bilateral & No & Operated \\
\hline 21 & $F$ & 33 & $1 y$ & $\begin{array}{l}\text { Grandmother, mother, } \\
\text { sister }\end{array}$ & $5-30$ years ago & Bilateral & No & 1 operated \\
\hline
\end{tabular}

Grade III (severe). SNAP non-recordable. DML prolonged $>4$ ms. CMAP decreased $<2 \mathrm{mV}$ ) or non-recordable. EMG showing massive or complete muscle denervation.

Basic demographic and clinical information was recorded in the questionnaire (Tab. 1). All participants were then asked whether they knew of any family members with carpal tunnel syndrome. In the event of a positive answer, patients were asked to indicate which of their relatives was affected, when the disease was diagnosed, which hand was involved, and how they were treated. All information was self-reported. If a given patient knew about a family member who suffered from CTS, but was unable to provide the required details (did not recall), this case was not considered as 'familial CTS'. The presence of comorbidities potentially predisposed to CTS was also recorded [6].

\section{Results}

Familial occurrence of the disease was noted in 21 patients (17\%): 16 women and five men. Three family members were affected in three patients, two relatives in eight patients, and one relative in 10 patients, giving a total of 35 affected relatives. Patients' sisters $(n=16)$ were the most commonly affected, followed by mothers $(\mathrm{n}=12)$, daughters $(\mathrm{n}=2)$, brothers $(\mathrm{n}=2)$, grandmothers $(\mathrm{n}=2)$ and an aunt $(\mathrm{n}=1)$. Bilateral manifestation of the disease was noted in 19 of 21 patients (90\%) and in 31 of $35(88 \%)$ of their affected relatives. The disease in patients' family members was diagnosed 2-30 years earlier than in the patients themselves. Thirteen of 35 relatives (37\%) were operated on. Three patients (14\%) had comorbidities potentially predisposed to CTS: two had diabetes and one underwent thyroidectomy. No systemic disease, neuropathy, history of wrist trauma, or drug use was noted in other patients.

\section{Discussion}

The results of this study show a fairly common (17\%) incidence of CTS among relatives of patients. This is significantly higher than in the general population (1\%) and in women $>40$ years old (5\%) [5]. This result does not automatically confirm the hypothesis of inheritability of the syndrome in some families. There are many factors predisposing to CTS, such as constitutional traits (short height, thicksetness and obesity), diseases (diabetes, hypothyroidism, rheumatoid arthritis) or developmental and anatomical changes of the carpal tunnel 
(4-8). Only some of them can be suspected of inheritability, but none were identified in our patients. Nevertheless, the occurrence of the syndrome in several members of one family may suggest that the risk of hereditary factors being present is higher than in the general population.

Several hereditary biochemical disorders have been identified predisposing to carpal tunnel syndrome, such as inheritable myopathies, familial hypercholesterolemia, familial amyloidosis, or hereditary neuropathy with liability to pressure palsies [9-11]. The incidence of CTS in families affected by these diseases is much higher than in the general population, and onset of the syndrome occurs early, usually in the second or third decade of life. Inheritable structural variations in the size of the tunnel or the volume of its contents have also been reported as predisposing to familial occurrence of the syndrome [12-14]. The results of our study also showed a significantly higher incidence of bilateral disease in patients with familial CTS: it occurred in 18 of 21 patients and in 31 of 35 their relatives. This finding was similar to that reported in a study by Alford et al.: $45 \%$ of patients with bilateral syndrome declared occurrence of the same symptoms in their family members, compared to $27 \%$ of patients with unilateral CTS declaring the same. The authors suggested the presence of inheritability of variations in the size of the carpal tunnel or its contents, which would manifest themselves bilaterally and may cause a predisposition for developing the syndrome [7].

The direct causes of idiopathic carpal tunnel syndrome remain obscure. Three different mechanisms are suspected to be involved in genetic predisposition to carpal tunnel syndrome: collagen synthesis, collagen degradation, and protection against oxidative stress effect in connective tissue. Several gene groups are involved in the regulation and modulation of these mechanisms, and results from the presented studies have shown their possible effect on the development of carpal tunnel syndrome. Variants within the COL1A1, COL5A1 and COL11A1 genes encoding synthesis of minor collagen subtypes may be potentially involved, as they alter the mechanical properties of tendons and other connective tissue structures within the carpal tunnel [15]. The collagen within connective tissue structures is also remodelled by matrix metalloproteinases (MMPs) and variants of these genes have also been investigated for their possible role in the risk of CTS development [16]. Next, the variants of genes encoding glutathione S-transferase synthesis were found to be involved in CTS aetiology [17]. These mechanisms may play a potential role as genetic risk factors in carpal tunnel syndrome and in its familial occurrence.

Self-reporting of the data placed unavoidable limitations on the accuracy of our data because we relied on patients' awareness of their family members' conditions. One may suspect that some of them, particularly in older age, might simply forget the presence of the disease in their relatives. In some families, their members live far away from each other and contact each other infrequently. We were not able to assess the degree to which our patients were underreporting family members with carpal tunnel syndrome of whom they were unaware. For this reason, the incidence of familial CTS in our material could be underestimated, in which case it emphasises still more the existence of the problem.

\section{Clinical implications and future directions}

The results of our study show that carpal tunnel syndrome has a moderate tendency to familial occurrence and that most familial cases occur in patients with bilateral disease. These findings seem not to have a direct translation into clinical practice, but may indicate the need for further investigations of this field. We believe that a question about family history should be added to the routine examination of each patient diagnosed with carpal tunnel syndrome.

\section{References}

1. TANZER RC. The carpal-tunnel syndrome; a clinical and anatomical study. J Bone Joint Surg Am. 1959; 41-A(4): 626-634, indexed in Pubmed: 13664702.

2. Phalen GS. Reflections on 21 years' experience with the carpal-tunnel syndrome. JAMA. 1970; 212(8): 1365-1367, indexed in Pubmed: 5467525.

3. Radecki P. The familial occurrence of carpal tunnel syndrome. Muscle Nerve. 1994; 17(3): 325-330, doi: 10.1002/mus.880170311, indexed in Pubmed: 8107710.

4. Gossett JG, Chance PF. Is there a familial carpal tunnel syndrome? An evaluation and literature review. Muscle Nerve. 1998; 21(11): 1533-1536, indexed in Pubmed: 9771681.

5. Atroshi I, Gummesson C, Ornstein E, et al. Prevalence of carpal tunnel syndrome in a general population. JAMA. 1999; 282(2): 153-158, indexed in Pubmed: 10411196.

6. Padua L, Coraci D, Erra C, et al. Carpal tunnel syndrome: clinical features, diagnosis, and management. Lancet Neurol. 2016; 15(12): 1273-1284, doi: 10.1016/S1474-4422(16)30231-9, indexed in Pubmed: 27751557.

7. Alford JW, Weiss APC, Akelman E. The familial incidence of carpal tunnel syndrome in patients with unilateral and bilateral disease. Am J Orthop (Belle Mead NJ). 2004; 33(8): 397-400, indexed in Pubmed: 15379235.

8. Żyluk A, Dąbal L, Szlosser Z. Constitutional factors and predisposition to carpal tunnel syndrome. Pol Orthop Traumatol. 2011; 76: 127-132.

9. Leifer D, Cros D, Halperin JJ, et al. Familial bilateral carpal tunnel syndrome: report of two families. Arch Phys Med Rehabil. 1992; 73(4): 393-397, indexed in Pubmed: 1554316.

10. Murakami T, Tachibana S, Endo Y, et al. Familial carpal tunnel syndrome due to amyloidogenic transthyretin His 114 variant. Neurology. 1994; 44(2): 315-318, indexed in Pubmed: 8309582.

11. Ihara $Y$, Nobukuni $K$, Namba $R$, et al. A family of familial hypercholesterolemia with cerebral infarction and without coronary heart disease. An unusual case with corneal opacity, polyneuropathy and carpal tunnel syndrome in the family: therapy with probucol and tocopherol nicotinate. J Neurol Sci. 1991; 106(1): 10-18, indexed in Pubmed: 1779233. 
12. Michaud LJ, Hays RM, Dudgeon BJ, et al. Congenital carpal tunnel syndrome: case report of autosomal dominant inheritance and review of the literature. Arch Phys Med Rehabil. 1990; 71(6): 430-432, indexed in Pubmed: 2185719.

13. Iannicelli E, Chianta GA, Salvini V, et al. Evaluation of bifid median nerve with sonography and MR imaging. J Ultrasound Med. 2000; 19(7): 481-485, indexed in Pubmed: 10898302.

14. Mahjneh I, Saarinen A, Siivola J. Familial carpal tunnel syndrome: a report of a Finnish family. Acta Neurol Scand. 2001; 104(6): 377-379, indexed in Pubmed: 11903093.
15. Dada S, Burger MC, Massij F, et al. Carpal tunnel syndrome: The role of collagen gene variants. Gene. 2016; 587(1): 53-58, doi: 10.1016/j. gene.2016.04.030, indexed in Pubmed: 27090000.

16. Burger MC, De Wet H, Collins M. Matrix metalloproteinase genes on chromosome 11q22 and risk of carpal tunnel syndrome. Rheumatol Int. 2016; 36(3): 413-419, doi: 10.1007/s00296-015-3385-z, indexed in Pubmed: 26521080.

17. Kim JK, Koh YDo, Kim JS, et al. Oxidative stress in subsynovial connective tissue of idiopathic carpal tunnel syndrome. J Orthop Res. 2010; 28(11): 1463-1468, doi: 10.1002/jor.21163, indexed in Pubmed: 20872582. 